Revista Água Viva

ISSN 1678-7471

\title{
RETRATOS DA LEITURA, RETRATOS DO LEITOR: GESTOS, ESPAÇOS, HÁBITOS
}

\section{PORTRAITS DE LECTURE, PORTRAITS DU LECTEUR: GESTES, ESPACES, HABITUDES}

\author{
Rita Jover-Faleiros ${ }^{1}$ \\ A leitura é sempre uma prática \\ encarnada em gestos, espaços, hábitos \\ Roger Chartier \\ História cultural: entre práticas e representações
}

DOI: 10.26512/aguaviva.v3i1.12201

Recebido em: 15 abr. 2018

Aceito em: 13 jun. 2018

RESUMO: O objetivo deste texto é de analisar os resultados relativos à 4a. edição da pesquisa Retratos da leitura no Brasil (Failla, 2016) do ponto de vista das representações sobre a atividade de leitura que ela veicula bem como a seleção dos enunciados selecionados pelos respondentes. Para o desenvolvimento da reflexão, mobilizamos as noções de representação tal como definida por Chartier (1985) e de leitura a partir dos trabalhos de Dumortier (2001), Gilson (2003), Kleiman (2002) e Brehm (2011).

Palavras-chave: Leitura; Representações da leitura; Representações; Retratos da leitura no Brasil.

RÉSUMÉ: L'objectif de ce texte est celui d'analyser les résultats relatifs à la 4e édition du sondage Retratos da leitura no Brasil (Portraits du lecteur au Brésil, Failla, 2016) du point de vue des représentations sur l'activité de lecture pour elle véhiculées dans les énoncés du sondage et du point de vue de la sélection des réponses au sondage. Pour développer l'analyse, nous travaillons la notion de représentation à partir de Chartier (1985) et la notion de lecture à partir des travaux de Dumortier (2001), Gilson (2003), Kleiman (2002) et Brehm (2011).

Mots-clés: Lecture; Représentations de la lecture, Représentations sociales, Portrait de la lecture au Brésil.

\footnotetext{
${ }^{1}$ Doutora em Letras pela Universidade de São Paulo (USP). Docente do Departamento de Letras da Universidade Federal de São Paulo (UNIFESP). E-mail: rita.jover@unifesp.br
} 
Neste artigo, analisamos as representações sobre a leitura contidas na pesquisa "Retratos da Leitura no Brasil” (Failla, 2016) e suas possíveis implicações quanto às práticas de leitura no contexto escolar brasileiro. Para isso, analisamos os dados referentes à representação da leitura veiculado pela referida pesquisa de duas formas: primeiramente, analisamos os enunciados formulados e constantes do instrumento de pesquisa do ponto de vista de sua formulação; em seguida, a maneira como os entrevistados selecionam esses enunciados. Finalmente, desenvolvemos uma reflexão acerca da relação entre esse binômio (formulação dos enunciados pelo instrumento de pesquisa e sua escolha pelos entrevistados) e os impasses relativos ao desenvolvimento do gosto pela leitura na escola.

Parece-nos importante destacar o papel dessas representações no que se refere às práticas de leitura na escola (e fora dela) porque são subjacentes à atividade de mais de uma maneira: seja porque orientam em parte as propostas curriculares de leitura e balizam a atividade docente, seja porque garantem sua consolidação, cristalizadas pelas representações, que continuam sendo veiculadas e apreendidas pelas sucessivas gerações de leitores.

Dessa forma, se um relativo senso comum sobre as problemáticas práticas de leitura no ensino básico é objeto de diagnóstico de especialistas na área - no Brasil, mas não só - uma das questões que se colocam, a nosso ver, ainda repousam na necessidade de se atentar justamente para como, seja na condição de pesquisadores, seja na condição de pesquisados, acabamos por ser vetores de determinadas representações acerca da leitura passíveis de cristalizar práticas de leitura das quais gostaríamos, como educadores, de nos afastar.

\section{Representações, práticas e construção de sentido(s)}

A fim de explorar as representações dos brasileiros sobre a leitura de acordo com os dados da pesquisa Retratos, cabe, antes, delimitar o conceito que subjaz a nossa interpretação dos dados e que nos permite elaborar hipóteses sobre seus resultados. Assim, como forma de desenvolver a análise, trabalhamos com o conceito de representação como instrumento teórico-metodológico para a compreensão das percepções e apreciações do real assim como definido por Roger Chartier, isto é: 
O modo como em diferentes lugares e momentos uma determinada realidade social é construída, pensada, dada a ler. [...] Classificações, divisões e delimitações que organizam a apreensão do mundo social como categorias fundamentais de percepção e de apreciação do real. [...] São esses esquemas intelectuais incorporados que criam as figuras graças às quais o presente pode adquirir sentido, o outro torna-se inteligível e o espaço possa ser decifrado. (Chartier, (1984[1988, p. 17])

Em nosso caso, discutimos a organização discursiva das formas de apreensão do mundo social por meio dos enunciados oferecidos aos entrevistados quando da pesquisa. Esses enunciados descrevem possibilidades de representações sobre a leitura, e sua análise oferece uma gama de representações sobre essa atividade que, definidas como “esquemas intelectuais incorporados” às práticas, condicionam as formas de produção e recepção de textos; nos modos como entendemos e desenvolvemos a leitura e seu ensino.

Pensar o conjunto de ações relacionadas à leitura e suas representações implica considerar, com Chartier, que "a leitura é sempre uma prática encarnada em gestos, espaços, hábitos" (op. cit. p. 178). O autor traduz de maneira sintética a complexidade das operações em jogo no ato da leitura ao considerar sua inscrição no tempo, na materialidade do suporte em que se lê, na subjetividade do gesto de quem lê condicionado pelo contexto - de ordem física, social, histórica, afetiva - em que se inscreve esse leitor. Entende, dessa forma, que se trata de processo de construção de sentido(s) historicamente determinado(s) realizado por sujeitos cuja leitura é condicionada pelas práticas de leitura de sua época, de sua inscrição social, institucional, de seus objetivos, de suas expectativas.

Nesse sentido, ainda que por caminhos distintos, os estudos na área da leitura e de seu ensino - sobretudo do ponto de vista das operações de ordem cognitiva desenvolvidos por autores como Kleiman (1989[2002]), Giasson (1990), Dumortier (2001), também consideram a complexidade do processo, descrito como sendo o resultado da relação de três componentes, a saber, o texto, o leitor e o contexto. Ainda que não tenhamos identificado trabalhos que apontem para a dimensão complementar dos trabalhos sobre representação e práticas de leitura desenvolvidos por Chartier (1984[1988], 1985[2001], 2013) ao modelo de compreensão escrita, sua convergência nos parece significativa por permitir discutir o impacto dos dados oferecidos pela pesquisa de forma matizada, pois cada um dos componentes do modelo de compreensão leitora nos parece permeado pelos elementos que se configuram como representações sobre a leitura e suas práticas. 
Com o objetivo de identificar de que maneira a articulação entre essas diferentes visadas são, a nosso ver, complementares e operantes para se pensarem as dimensões teóricas e práticas da leitura e de seu ensino, fazemos uma breve síntese dos componentes do modelo de compreensão escrita.

Dumortier (2001, p. 17) descreve cada um dos componentes do modelo de compreensão leitora como um “conjunto de variáveis". O processo de construção de sentido na leitura é, segundo o autor, resultado da relação desses conjuntos de variáveis entre si. Em razão de sua complexidade, cada um desses conjuntos se configuraria em uma força. Três forças em relação, respectivamente, força-leitor, força-texto e forçacontexto.

A força-leitor reúne a descrição do conjunto de estruturas de ordem afetiva e cognitiva e dos processos postos em ação pelo sujeito com o objetivo de construir sentido no ato da leitura. Enquanto estruturas afetivas do leitor dizem respeito a seus interesses e projetos, as cognitivas se traduzem em conhecimentos de ordem linguística (conhecimentos fonológicos, sintáticos, morfológicos, semânticos e pragmáticos) e conhecimentos de mundo que, no âmbito da leitura, são pensados como o acúmulo de experiências armazenadas pelo sujeito na forma de esquemas.

Ambas as estruturas, afetivas e cognitivas, são constitutivas do sujeito independentemente de qualquer situação de leitura. Aquilo que é singular a cada situação de leitura é a forma como o leitor mobiliza essas estruturas por meio de diferentes processos que atuam concomitantemente, fazendo com que interajam essas duas dimensões com vistas a operar a compreensão textual.

Esses processos de leitura são distinguidos em cinco operações (Dumortier, 2001, Giasson, 2003): os microprocessos (responsáveis pelo tratamento da informação no nível da frase), os processos de integração (procedimentos de identificação dos referentes na constituição da rede anafórica e dos conectores com vistas ao desenvolvimento da progressão textual e de inferências baseadas nos esquemas acionados para uma leitura dada), os macroprocessos (identificação das ideias principais por meio da habilidade de se resumir um texto e/ou suas partes organizado a partir de sua estrutura), os processos de elaboração (habilidade de se fazer predições sobre a leitura a partir do lido, constituição de imagem mental do lido, resposta afetiva a essa imagem mental, estabelecimento de relação entre essa imagem e conhecimentos de mundo do leitor, reflexão sobre o lido) e, por fim, os processos metacognitivos (habilidade de identificar equívocos de leitura, 
perda da compreensão no processo e possibilidade de reparação e retomada).

A força-contexto é composta pelas dimensões circunstanciais de tempo e de espaço institucionais, pelo status e papel atribuído ao leitor nessas circunstâncias, e pelas práticas de leitura (maneiras de ler, modalidades de manifestação da compreensão), e a força-texto se constitui, segundo Dumortier, em:

um artefato dotado de um poder de estimular o leitor ao amalgamar uma construção linguística organizando, em diferentes planos (intenção, enunciação, coesão, conexão, segmentação, programação) e passível, pois, de julgamento de coerência [e] uma produção sociocultural estruturada por códigos adicionais, passível, por sua vez, de julgamentos de gosto e de valor (op. cit., 2001, p. 17).

Cada um dos componentes constitutivos do modelo de compreensão escrita descrito é orientado pelas condições de produção e de recepção. Dessa forma, na relação que estabelecem entre si, quando de uma situação de leitura, as forças leitor, texto e contexto estão em contato de modo a projetarem expectativas quanto ao modo de gerarem e produzirem sentido. A leitura é determinada pela gestualidade do leitor na definição do projeto para uma dada leitura em razão do contexto em que se encontra. A resultante da tensão entre essas três forças, ou seja, a leitura, é, pois, sobredeterminada pelas representações e práticas de cada um desses três componentes (ou dessas três forças) e das três em relação entre si.

Na complexa atividade da leitura estão em jogo, pois, elementos de ordem individual e de ordem coletiva: o leitor, sujeito capaz de fazer interagir cognição, afetividade, percepção (Brehm, 2011) organizados sob a forma de um projeto, pois a leitura implica uma iniciativa de alguma ordem, uma realização, uma transitividade - leio para estudar/aprender, leio por prazer para entrar em contato com determinada obra ou autor.

Os diferentes projetos de leitura podem ter uma motivação do leitor ou serem definidos institucionalmente, ou ainda que não explicitamente constitutivos de uma seleção bibliográfica dada, também podem ser leituras que contribuam para um objetivo institucionalmente definido. Em todos os casos, para não nos estendermos na miríade dos exemplos possíveis, o leitor delineia expectativas em relação ao que lê e ao modo de fazêlo (Kleiman, 1989[2002]) que são, por sua vez, configurados, simultaneamente, pelas representações e práticas que desenvolveu, individualmente, ao longo de sua experiência 
como leitor e pelas representações e práticas de leitura em vigor no ambiente em que lê.

Destacamos aqui a importância de se entender que não é possível discernir duas ordens (externa e interna do sujeito leitor) como sendo absolutamente distintas, mas sim como dimensões em relação contínua. É sobre essa relação que propomos discutir e é sobre ela que as possíveis contribuições do ponto de vista didático e metodológico podem operar.

É possível compreender diante do exposto que a construção de uma imagem mental acerca do texto lido é resultado da série de operações, inputs em contextos diversos, mas que, neste complexo da interação das três forças (texto-leitor-contexto), as representações acerca da leitura e dos modos de ser leitor orientam a própria configuração da imagem mental acerca do que se lê. É sobre essas representações sobre a leitura que, neste trabalho, tratamos de discutir a partir dos dados oferecidos pela pesquisa Retratos.

\section{Retratos da leitura, retratos do leitor}

Divulgada em 2016, a $4^{\mathrm{a}}$ edição da pesquisa Retratos desenha, de forma quantitativa, o perfil de leitores brasileiros. Iniciativa do Instituto Pró-Livro, a abrangência geográfica da pesquisa é nacional, tendo sido entrevistados 5012 brasileiros com 5 anos ou mais, alfabetizados ou não, em 315 municípios brasileiros. Do ponto de vista conceitual, o desenvolvimento do instrumento de pesquisa contou com a consultoria dos especialistas da área leitura, além de orientações do Centro Regional para el Fomento del Libro en América Latina y el Caribe (Cerlalc/Unesco) e sua aplicação foi realizada pela instituição IBOPE Inteligência. Os objetivos específicos da pesquisa foram:

Conhecer o comportamento leitor do brasileiro e compará-lo ao não leitor, [...]. Hábitos e preferências, barreiras, influências e representações sobre a leitura (no imaginário coletivo). Leitura de livros digitais, leitura em meio digital e uso de diferentes materiais, suportes e dispositivos para a leitura. Identificar os indicadores de leitura e construir séries históricas. Identificar formas de acesso e avaliar uso das bibliotecas - públicas e escolares (Failla, 2016, p. 163).

Para fins de definição, o termo leitor designa, na pesquisa Retratos, "aquele que leu, inteiro ou em partes, pelo menos 1 livro nos últimos 3 meses"; e não leitor designa "aquele que declarou não haver lido nenhum livro nos últimos três meses, mesmo que tenha lido nos últimos doze meses" (op. cit., 2016, p. 184). Trata-se, evidentemente, de 
trabalho abrangente e cujos dados oferecerem fonte profícua para a pesquisa em diferentes áreas de conhecimento e que não são, neste trabalho, discutidos em sua totalidade. Recortamos aqui, no conjunto dos dados oferecidos pela pesquisa Retratos, os dados referentes às representações sobre a leitura dos entrevistados obtidos na $4^{\mathrm{a}}$ edição da pesquisa ${ }^{2}$.

Dentre esses dados, nos interessa especialmente o fato de a pesquisa dedicar, de forma explícita, uma seção às representações da leitura (op. cit., p. 240-243), ainda que, ao longo das demais seções, também subjazam representações referentes à leitura como forma de se construir um retrato do estado da leitura no Brasil na atualidade.

A pergunta formulada nesta seção específica foi: "qual das seguintes frases que eu vou ler mais se aproxima do que significa leitura para você? E em segundo lugar?”. Os onze enunciados oferecidos aos entrevistados foram:

1) a leitura traz conhecimento; 2) a leitura traz atualização e crescimento profissional; 3) a leitura me ensina a viver melhor; 4) a leitura pode fazer uma pessoa 'vencer na vida' e melhorar sua situação financeira; 5) a leitura é uma atividade interessante; 6) a leitura facilita a aprendizagem na escola ou faculdade; 7) a leitura é uma atividade prazerosa; 8) a leitura ocupa muito tempo; 9) a leitura é uma atividade cansativa; 10) só leio porque sou obrigado(a); 11) a leitura não serve pra nada. (op. cit., p. 240).

Além dos onze enunciados, há também uma $12^{\mathrm{a}}$ opção: "Nenhuma destas/Não sabe/Não respondeu". Dividimos os onze enunciados oferecidos aos entrevistados para representar a leitura em dois grandes grupos. O primeiro se configura por representações cuja visada é de ordem funcional, ou seja, da leitura como instrumento ou meio para outra finalidade, investida de valor em razão do benefício que possa vir a gerar (o conhecimento, crescimento profissional, a aprendizagem, as melhorias nas condições socioeconômicas etc.).

A essa primeira visada associamos os enunciados 1, 2, 3, 4, 6 e 11 (seis dos onze enunciados). Em contraste ao caráter predominantemente transitivo configurado pelo primeiro grupo de enunciados, o segundo grupo traz enunciados de ordem predicativa acerca da leitura que não apontam para uma externalidade, e sim para seu próprio exercício, classificando a leitura como uma atividade "prazerosa", "interessante" ou

\footnotetext{
${ }^{2}$ Desenvolvemos, concomitantemente, uma investigação de fôlego maior com o objetivo de analisar a evolução desses dados na série histórica de 2000 a 2016, intervalo em que se registram quatro edições da pesquisa e nas quais as representações são apresentadas de forma distintas.
} 
“cansativa". Nesse segundo grupo, inscrevemos os enunciados 5, 7, 8, 9 e 10.

Observamos, já incialmente, uma disparidade na distribuição do número de enunciados, seis relativos ao primeiro grupo e seis, ao segundo. Se dentro de cada grupo há uma valoração entre os enunciados, como, por exemplo, na oposição entre o primeiro enunciado do primeiro grupo (“a leitura traz conhecimento”) e o décimo primeiro ("a leitura não serve para nada") e, no segundo grupo, entre o quinto ("a leitura é uma atividade interessante") e o décimo ("só leio porque sou obrigado"); não há articulação entre essas duas dimensões passíveis de estarem presentes na leitura: o prazer e interesse na aprendizagem ou o conhecimento acerca das razões por que a leitura pode ser interessante e/ou prazerosa.

No primeiro grupo de enunciados, identificamos uma relação entre a atividade da leitura e o ensino, uma vez que todas veiculam uma forma de aprendizagem proporcionada pela leitura (o conhecimento, o crescimento profissional, a possibilidade de se "vencer" na vida e a melhora das condições financeiras). Assim, ler está associado à assimilação de novos saberes positivamente valorados e promovidos pela articulação entre a leitura e o ensino. Ainda que a referência ao ensino formal seja explícita apenas no enunciado de número 6, o aporte de conhecimento por meio da leitura (enunciado de número 1) e a presença do verbo "ensino" (enunciado de número 3 ) remetem ao universo da escola, ainda que essa não seja explicitamente referida.

Entendemos que, do ponto de vista da representação, por remeterem às práticas de leitura aprendidas e desenvolvidas na e pela escola, os enunciados desse grupo, ao serem proferidos pelos entrevistadores, acionam, possivelmente, nos entrevistados, esquemas mentais relacionados ao campo das práticas escolares e isso por duas razões. Em primeiro lugar porque a aprendizagem da leitura, da alfabetização às leituras literárias para fins de exames de concursos vestibulares é uma das atividades mais presentes na instituição escolar e, em segundo lugar, em razão da escolha lexical registrada nos enunciados desse grupo, que o relacionam, conforme já exposto acima, ao campo semântico do universo escolar. Dessa forma, esses enunciados veiculariam não apenas a uma representação sobre a leitura, mas também (e sobretudo, a nosso ver) uma maneira de ser leitor, uma gestualidade que traduz hábitos em espaços determinados, uma forma de ser leitor em relação a um texto num dado contexto.

No segundo grupo, constam enunciados predominantemente construídos a partir de um predicativo do sujeito "A leitura é prazerosal interessantel cansativa". Essas 
enunciados não inscrevem a leitura em um contexto específico nem remetem a atividade a uma terminalidade que não a própria leitura (em contraste com os enunciados do primeiro grupo que a associam a um ganho, uma mudança de status, uma apropriação de saberes).

Nesse sentido, os enunciados do segundo grupo focalizam uma apreciação de cunho valorativa da própria atividade, podendo vir a mobilizar a relação dos entrevistados com a leitura e sua representação desvinculadas das práticas escolares de leitura - ainda que, para os entrevistados, a leitura talvez não possa vir a ser desvinculável de suas práticas escolares, justamente por ser este o lugar em que desempenha, ao mesmo tempo, papel de meio e de objeto de ensino e de aprendizagem.

Dessa forma, os enunciados relativos às representações sobre a leitura cristalizam, em linhas gerais, duas duplas de posições (em antagonismo?): aprendo versus não aprendo com a leitura e gosto versus não gosto de ler. Essa oposição é ainda mais significativa em razão da maneira como os enunciados são oferecidos para a seleção: os entrevistados deviam escolher duas, entre as doze possibilidades (incluindo-se aqui a $12^{\mathrm{a}}$ "Nenhuma destas/Não sabe/Não respondeu”).

Interessa-nos observar como essa seleção foi composta, como se distribuem os enunciados dos dois grupos. Se de maneira complementar, em que um enunciado de cada um dos dois grupos, com valor positivo ou negativo, estão nas primeiras posições, por exemplo, numa escolha em que a primeira posição seja "a leitura é uma atividade interessante" e "a leitura traz conhecimento" ou se, na distribuição das escolhas, predomina um grupo (em detrimento do outro) nas preferências das escolhas dos entrevistados.

$\mathrm{Na}$ pesquisa Retratos, as respostas obtidas referentes ao conjunto dos doze enunciados são apresentadas de quatro maneiras. Primeiramente, são oferecidos os dados gerais relativos ao conjunto das respostas dos 5012 entrevistados. Em seguida, os dados são organizadas em função de três critérios: por perfil (leitor/não leitor); por escolaridade (não alfabetizados/Ensino Fundamental I/Ensino Fundamental II/ Ensino Médio/ Superior) e por classe social (A/ B/ C/ D e E).

Nos quatro grupos de resposta (geral, por perfil, por escolaridade e por classe), os dois enunciados mais bem classificados (em primeiro e segundo lugar) foram, respectivamente, o $1^{\circ}$ e $2^{\circ}$ enunciados do grupo 1 ("a leitura traz conhecimento"; "A leitura traz atualização e crescimento profissional"). No quadro geral, o primeiro 
enunciado foi escolhido por $49 \%$ dos entrevistados e o segundo, por $23 \%$. No contraste por perfil (leitor/não leitor), $53 \%$ dos leitores escolheram o $1^{\circ}$ enunciado contra $43 \%$ dos não leitores; o $2^{\circ}$ enunciado foi escolhido por $26 \%$ dos leitores contra $19 \%$ dos não leitores. Na segmentação das escolhas por escolaridade, o $1^{\circ}$ enunciado é o primeiro escolhido (dos não alfabetizados até os entrevistados de nível superior), o $2^{\circ}$ enunciado varia de posição de acordo com a faixa de escolaridade de maneira crescente (14\% das escolhas entre os não alfabetizados, 16\% para o Fundamental I, 20\% para o Fundamental II, 28\% para o Ensino Médio e 34\% para o Superior). Finalmente, no recorte por classe social, o $1^{\mathrm{o}}$ enunciado foi escolhido em primeiro lugar por todos os segmentos, numa variação crescente por renda das classes D/E (41\%), passando pela classe C (50\%), pela classe B $(53 \%)$ chegando à classe A $(56 \%)$.

É possível observar, pois, que dois dos enunciados do primeiro grupo, que traduzem, a nosso ver, representações da leitura atreladas a sua prática em contexto escolar são as mais escolhidas nos quatro recortes diferentes do quadro (geral, por perfil leitor/não leitor, por escolaridade e por classe social), o que nos parece ser, por si, bastante significativo da maneira, do lugar e dos papéis da leitura no Brasil a partir do que a pesquisa retrata. E o que dizer sobre a escolha dos enunciados do segundo grupo nos diferentes segmentos, como os enunciados foram escolhidos, que posição ocupam e o que possivelmente subjaz a essas escolhas?

Analisados os dados do quadro geral dos entrevistados, os enunciados do segundo grupo ("a leitura é uma atividade interessante", "a leitura é uma atividade prazerosa", "a leitura ocupa muito tempo", "a leitura é uma atividade cansativa") ocupam, respectivamente, as $5^{\mathrm{a}}, 7^{\mathrm{a}}, 8^{\mathrm{a}}, 9^{\mathrm{a}}$ e $10^{\mathrm{a}}$ posições entre as escolhas dos 5012 entrevistados na pesquisa Retratos.

Os dados relativos ao recorte por perfil (leitor/não leitor) são bastantes próximos aos dados oferecidos pelo quadro geral. Entre os leitores, o enunciado de número 5 (“a leitura é uma atividade interessante") foi escolhido por $18 \%$ dos entrevistados, o enunciado de número 7 (“a leitura é uma atividade prazerosa”), por 17\%, o que coloca ambos os enunciados aproximadamente na mesma posição entre os leitores (a título de rememoração, a pesquisa classifica como sendo leitores aqueles que leram um livro ou parte dele nos últimos três meses); na oposição valorativa, os leitores cuja representação sobre a leitura é negativa são menos numerosos: os enunciados 8, 9 e 10 ("a leitura ocupa muito tempo", "a leitura é cansativa" e "só leio porque sou obrigado") são escolhidos por 
uma baixa porcentagem dos entrevistados leitores: $3 \%, 2 \%$ e $2 \%$ respectivamente.

Entre os não leitores, o enunciado de número 5 responde por $13 \%$ das escolhas, o que o coloca em uma posição próxima da escolhas dos leitores (18\%) e do quadro geral (16\%) e, como veremos em seguida, também no corte por escolaridade e por classe social. Os números indicam uma alteração mais expressiva no tocante aos demais enunciados: $9 \%$ dos não leitores definem a leitura como algo prazeroso, $8 \%$ como uma atividade que ocupa muito tempo e é cansativa, 5\% acham ler cansativo. Por fim, 8\% optaram por uma última alternativa: "nenhuma destas/ não sabe/ não respondeu".

Ao se olharem os dados relativos às escolhas dos enunciados pelo critério de escolaridade (repartidos entre não alfabetizados a entrevistados com nível superior), o $5^{\circ}$ enunciado ("a leitura é uma atividade interessante") varia entre 15 e $18 \%$ das escolhas. Chamamos atenção aqui para a escolha de $16 \%$ dos não alfabetizados por esse enunciado, o que pode apontar para uma representação bastante arraigada de sujeitos que, apesar de não haverem passado pela experiência da leitura, pensam se tratar de uma atividade interessante, seja pela observação, seja pela transmissão de um valor no meio em que vivem. O prazer relativo à leitura ( $7^{\circ}$ enunciado) sofre uma escolhe variada em função do segmento escolar. Entre os não alfabetizados, 8\%; Fundamental I, 13\%, Fundamental II, 10\%; e Ensino Médio, 13\%; Ensino Superior, 22\%. Ao se refletir sobre esses números (e só sobre eles), é interessante observar a como dois grupos escolhem o $7^{\circ}$ enunciado: $8 \%$ entre os não alfabetizados e $22 \%$ dos entrevistados do nível superior.

Apontamos duas pistas de investigação referentes a esse último dado: os $22 \%$ dos entrevistados que têm nível superior e que acham a leitura uma atividade prazerosa foram desenvolvendo essa percepção ao longo de seu processo de escolarização, principalmente em sua última fase ou por que o prazer na leitura permitiu que fossem mais longe em seu processo de escolarização? Essa última hipótese pode ser corroborada se associada ao $1^{\circ}$ enunciado do grupo 1 ("a leitura traz conhecimento"), que responde a 58\% das escolhas contra os $2 \%$ dos entrevistados desse segmento para quem a percepção da leitura é de uma atividade exclusivamente compulsória ("só leio porque sou obrigado").

As escolhas referentes às percepções negativas da atividade de leitura ("ocupa muito tempo", "é cansativa" e só exercida "por obrigação") oscilam de maneira não homogênea se considerada a progressão no processo de escolarização (dos não alfabetizados aos de nível superior). Observa-se, contudo, uma pequena redução dessa percepção quanto mais escolarizados são os respondentes. 
Finalmente, com relação ao segundo grupo de enunciados e o corte por classe social, o $5^{\circ}$ enunciado ("a leitura é uma atividade interessante") responde, respectivamente, por $11 \%, 18 \%, 16 \%$ e $15 \%$ das escolhas das classes $\mathrm{A} / \mathrm{B} / \mathrm{C} / \mathrm{D}$ e $\mathrm{E} . \mathrm{O} 7^{\circ}$ enunciado ("a leitura é uma atividade prazerosa") tem $21 \%$ das escolhas entre os entrevistados da classe A, $18 \%$ da classe B, $12 \%$ da C e $10 \%$ das classes D e E. Os demais enunciados que atribuem um valor negativo à atividade da leitura ("ocupa muito tempo", "cansativa", "só leio porque sou obrigado") representam porcentagens relativamente baixas entre as escolhas dos entrevistados (se considerados os demais números), entre 0 e $5 \%$.

Destacamos, pois, a relação que os dados permitem estabelecer entre leitura e prazer para os respondentes da classe social de tipo A e os de nível superior. Para esses segmentos, o prazer na atividade da leitura aparece em $3^{\text {a }}$ posição nas escolhas dos enunciados, o que nos levaria à conclusão de que a percepção da leitura como uma atividade prazerosa estaria restrita, de maneira expressiva, à classe social e ao nível de escolarização.

É possível, sim, que, por um lado, as melhores condições de infraestrutura na formação escolar daqueles que dispõem de mais renda criem um contexto que favoreça o desenvolvimento do gosto pela leitura e que, nesse ciclo virtuoso, a valorização da leitura como uma atividade intransitiva (uma espécie de fim em sim mesmo) e não um meio para outra finalidade, ou, nas palavras de Bourdieu (1979[2006]), na tensão, respectivamente, entre as disposições de ordem estética e ética na formação do gosto em que a primeira se traduziria numa "experiência de mundo liberada das pressões materiais e das urgências temporais, além da prática de atividades cujas finalidades se encontrem nelas mesmas" (Rodella, 2013, p. 41); enquanto o segundo estabeleceria uma relação de funcionalidade no consumo de bens culturais. Mas, como bem aponta a pesquisadora Gabriela Rodella (op. cit.), a partir dos trabalhos de Lahire (2002[2004]), não é possível entender essas disposições como suficientes nas imbricadas relações em contextos distintos em que a produção e consumo de bens culturais se dá. Dessa forma, nas palavras da pesquisadora:

há que se considerar a complexa articulação entre as preferências dos leitores e a produção dos textos, a idealização da recepção por parte dos produtores de livros e as práticas efetivas daqueles que deles se apropriam, sempre criadoras de usos e normas representações em geral irredutíveis à vontade dos produtores de discursos e normas (Rodella, 
op. cit., p. 45)

Se fosse possível reduzir a percepção da leitura como uma atividade prazerosa à origem social e à escolaridade, muito provavelmente os resultados da pesquisa Retratos traria dados diferentes dos vistos, e os enunciados dos dois grupos seriam classificados de maneira inversa e distinta em função dos três critérios de exposição dos dados (perfil, escolaridade e classe social). Não é isso, entretanto, que a pesquisa Retratos informa. Nela, como descrito acima, há uma relativa homogeneidade na distribuição das escolhas dos enunciados no quadro geral dos dados e na divisão pelos critérios referidos, inclusive com um gradiente relativamente estreito, no recorte de escolarização, na escolha dos enunciado de número 5 ("a leitura é uma atividade interessante") variando de 15 a $18 \%$ dos não alfabetizados aos respondentes de nível superior e de 8 a 13\% na escolha do enunciado de número 7 ("a leitura é uma atividade prazerosa"); além da convergência absoluta, não importando o recorte dos dados oferecido, na escolha do $1^{\circ}$ enunciado ("a leitura traz conhecimento").

Cabe observar que os dados registrados reforçam o que discutem Ezequiel Theodoro da Silva (2012) e Regina Zilberman (2012) a propósito da oposição entre o dever ler e o prazer de ler na análise dos dados referente à $3^{a}$ edição da pesquisa Retratos, bem como o que Assumção (2008), na $2^{\mathrm{a}}$ edição da pesquisa, também destaca. Há, parecenos, no que se refere às visadas referentes à leitura, uma pista de trabalho a ser explorada.

Lemos, nos dados referentes às representações sobre a leitura, um fenômeno que parece, de modo mais predominante, socialmente compartilhado, sob a forma de discursos em vigor sobre a leitura do que propriamente como fenômenos experenciados pelos entrevistados. Nesse sentido, entendemos que a própria formulação e apresentação dos enunciados propicia ou, de certa maneira, reforça a clivagem na representação da leitura como algo funcional ou como algo prazeroso; aproximando as representações sobre a leitura com as representações sobre a escola, confundindo-as.

\section{CONSIDERAÇÕES FINAIS}

É certo que a leitura é uma atividade eminentemente escolar que organiza as demais atividades do conjunto das diferentes disciplinas nela e por ela ensinadas, e a expressiva escolha do primeiro grupo de enunciados parece traduzir essa percepção da 
atividade da leitura como escolar, numa fusão das representações. Essa percepção pode indicar, a nosso ver, que parte dos entrevistados não se apropria da atividade da leitura de modo a desvinculá-la do contexto exclusivamente escolar. Talvez a pesquisa Retratos mostre como efetivamente a leitura esteja presente em nossas vidas: na maior parte do tempo e independentemente da escolarização e da classe social, ela é um meio para outro fim e se realiza de forma predominante na escola.

Para uma porcentagem baixa da população, concentrada entre os mais ricos e/ou mais escolarizados, ela também seja percebida como interessante e prazerosa. Entendemos, também, entretanto, que o retrato das representações sobre a leitura tal como se apresenta na pesquisa (e na maneira como o analisamos) é um dos elementos que contribuem para que a apropriação e autonomia dos leitores permaneça uma questão para a investigação no Brasil, no sentido de desenvolver recursos e propostas de ordem metodológica que possibilitem que o brasileiro leia mais e melhor.

Seria possível, talvez, entender que há algo no modo como nós, educadores, abordamos a leitura na intuição escolar que fomenta a clivagem apontada e que falhemos ao articular os enunciados de número 1, 5 e 7 de forma disseminada como representação da atividade da leitura? Em outras palavras, falharíamos na articulação entre conhecimento, interesse e prazer na formação dos leitores? Será que, como apontam alguns pesquisadores da área de ensino da leitura literária, como Rouxel (2004[2012], 2012), Langlade (2004[2012]) e Jouve (2004[2012]), talvez haja uma articulação possível entre o dever ler e o prazer de ler que possa ser desenvolvida pela via da experiência do sujeito leitor que se apropria e atribui sentido à atividade e que isso implique o desenvolvimento de uma autonomia do leitor em relação à instituição escolar?

Sejam quais forem as possíveis respostas às questões formuladas, parece-nos que entender o papel que as representações exercem na formação e na atividade de leitura é algo bastante profícuo em dois planos: seja, numa dimensão ampla das representações e práticas de leitura de uma dada coletividade e que informam seus objetivos e seu lugar no seio dessa coletividade; seja numa dimensão mais pontual na análise do papel dessas representações na configuração dos três componentes do modelo de compreensão escrita (texto, leitor e contexto). E isso como forma de se pensarem modelos metodológicos para a formação do leitor em contexto escolar, considerando, em última análise, que o conjunto de respostas colhidas na pesquisa Retratos é também o resultado do encontro do leitor com o texto em um contexto, e que as representações e práticas sociais de seu relativas à 
leitura sobredeterminam a leituras dos enunciados sobre as representações sobre a leitura, em uma espiral contínua.

\section{REFERÊNCIAS}

ASSUMÇÃO, J. Leitura cultural, crítica ou utilitária. In: GALENO, A. (Org.) Retratos da leitura no Brasil. São Paulo: Imprensa Oficial/ Instituto Pró-livro, 2008.

BOURDIEU, P. A distinção. Porto Alegre/São Paulo: Zouk/Edusp, 1979[2006].

BREHM, S. Du sens aux sens: les représentations mentales dans l'acte de lecture. In: Protée, v. 39 n. 2, p. 107-112. Université du Québec à Chicoutini: Département de des arts et lettres, 2011.

CHARTIER, R. (Dir.). Práticas de leitura. São Paulo: Estação Liberdade, 1985[2001]. . A história cultural: entre práticas e representações. Lisboa: Difel, 1984 (2002]. . Uma trajetória intelectual: livros, leituras, literaturas. In: ROCHA, J.C.C. (Org.) A força das representações: história e ficção. Chapecó: Argos, 1984 [2002].

DUMORTIER, J. L. Lire le récit de fiction. Pour étayer un apprentissage: théorie et pratique. Bruxelles: De Boeck Duculot, 2001.

FAILLA, Z. (Org.) Retratos da leitura no Brasil. Rio de Janeiro: Sextante, 2016.

GIASSON, J. La lecture: de la théorie à la pratique. Québec: G. Morin, 2003. KLEIMAN, A. Texto \& Leitor. Aspectos cognitivos da Leitura. São Paulo: Pontes, 1989[2002].

JOVER-FALEIROS, R. Sobre o prazer e o dever ler. In: DALVI, M. A.; REZENDE, N.; JOVER-FALEIROS, R. (Orgs.). Leitura de literatura na escola. São Paulo: Parábola. p. 113-134, 2013.

JOUVE, V. A leitura como retorno a si: sobre o interesse pedagógico das leituras subjetivas. In: ROUXEL, A.; LANGLADE, G.; REZENDE, N. (Orgs.) Leitura subjetiva e ensino de literatura. São Paulo: Alameda editorial. p. 55-67, 2004[2012].

LAHIRE, B. Retratos sociológicos: disposições e variações individuais. Porto Alegre: Artmed, 2002[2004].

Rodella, G.O. As práticas de leitura literária de adolescentes e a escola: tensões e influências. Tese (Doutorado em Educação) PPGE/USP, São Paulo, 2013. 
ROUXEL, A. Práticas de leitura: quais rumos para favorecer a expressão do sujeito leitor. In: Cadernos de pesquisa. v. 42, n. 145, p. 272-283, 2007[2012].

SILVA, E. T. A escola e a formação dos leitores. In: FAILLA, Z. (Org.) Retratos da leitura no Brasil 3. São Paulo: Instituto Pró livro/Imprensa oficial, 2012.

ZILBERMAN, R. Ler é dever, livro é prazer? In: FAILLA, Z. (Org.) Retratos da leitura no Brasil 3. São Paulo: Instituto Pró livro/Imprensa oficial, 2012.

RHODEN, C. Nunca me sonharam. DVD. Colorido. BRA, 2017.

JARDIM, J. Pro dia nascer feliz. DVD. Colorido, BRA, 2005. 